\title{
The prevalence of risk factors associated with non-communicable diseases in Afghan refugees in southern Iran: a cross-sectional study
}

Erfan Taherifard', Mohammad Javad Moradian², Ehsan Taherifard³, Abdolrasool Hemmati ${ }^{3}$, Behnaz Rastegarfar ${ }^{4}$ and Hossein Molavi Vardanjani ${ }^{*}$

\begin{abstract}
Background: Refugees are highly vulnerable to many health-related risks. Monitoring non-communicable diseases (NCDs) is of overriding importance in these populations. This study aimed to investigate the prevalence of risk factors for NCDs amongst Afghan refugees in a refugee camp located in southern Iran.

Methods: This cross-sectional sturdy was conducted in 2018. Risk factors such as inadequate nutrition, physical inactivity, tobacco smoking, obesity and overweight, hypertension (HTN), elevated fasting plasma glucose (FPG), and dyslipidaemia were assessed. Data were gathered with a modified WHO STEPS procedure. Prevalence and agestandardized prevalence and their 95\% confidence intervals (CI) were estimated.

Results: The estimated prevalence were $94 \%$ for inadequate fruit/vegetable consumption, $18 \%$ for physical inactivity, 9\% for tobacco smoking, 3\% for FPG, 20\% for HTN, 51\% for central obesity, 24\% for overweight, 19\% for obesity, and 69\% for dyslipidaemia.

Conclusions: Except for inadequate fruit and vegetable intake and dyslipidaemia, the prevalence of other NCD risk factors was low among Afghan refugees in Iran. Raising awareness about healthy diet and its importance and the provision of more affordable fruit and vegetables are two effective measures toward improving the health of refugees in Iran.
\end{abstract}

Keywords: Health survey, Refugees, Risk factor, Non-communicable diseases

\section{Background}

Refugees, as a vulnerable population [1], have higher risks of developing mental $[2,3]$ and physical [4] disorders [5]. In addition to higher rates of infectious diseases [6], the prevalence of non-communicable diseases (NCDs) and their risk factors are rising in these populations $[7,8]$.

\footnotetext{
* Correspondence: hosseinmolavi@ymail.com

'MPH Department, Medical School, Shiraz University of Medical Sciences, Setad Square, Shiraz, Fars, Iran

Full list of author information is available at the end of the article
}

The largest and fastest growing proportion of the global burden of diseases is attributed to NCDs $[9,10]$, particularly in low- and middle-income populations. Therefore NCD control is a worldwide priority [11]. Controlling NCDs requires a shift to primary prevention by tackling key modifiable risk factors including inadequate nutrition, physical inactivity, alcohol consumption, smoking, high blood pressure, and dyslipidaemia $[12,13]$. Therefore, monitoring the current status of these key risk factors is an essential element of $\mathrm{NCD}$ control. 
The Islamic Republic of Iran has been hosting Afghan refugees since the 1980s [14]. In July 2017, it was reported by the United Nations High Commissioner for Refugees (UNHCR) that more than 950,000 Afghan refugees were residing Iran [15]. Most of this population consists of the progeny of two main waves of asylum seekers who fled Afghanistan and entered Iran after the invasion of Soviet troops in 1979 and during the Taliban rule era from 1996 to 2001 [16, 17]. However, the majority of them are unable to gain citizenship [18], and so are not included in health screening programs such as STEPwise approach to surveillance (STEPS). Accordingly, the current status and prevalence of key risk factors of NCDs are unknown among Afghan refugees in Iran.

To date, seven rounds of national surveillance studies of risk factors for NCDs have been conducted in Iran since 2005. According to the latest study in 2016, inadequate fruit and vegetable intake, abnormal lipid profile and insufficient physical activity comprised the three most prevalent risk factors among the Iranian population at 82, 69 and 56\%, respectively [19]. Although there is no national NCDs surveillance in Afghanistan, two studies assessed the prevalence of risk factors for NCDs in Jalalabad and Kabul [20, 21]. In the Kabul study it was reported that the prevalence of obesity and hypertension (HTN) were 31 and 33\%, respectively.

The present study was conducted to assess the current status of prevalence of the most common risk factors for NCDs with a modified World Health Organisation (WHO) STEPS procedure.

\section{Methods}

This survey was conducted in one of the eight registered Afghan refugee camps, located in southern Iran. This camp was selected as a convenient study setting. Because of executive and legal issues the study had not applicability to be conducted in other camps. In this camp, almost all primary and outpatient healthcare services are provided by a single healthcare centre funded by the UNHCR. One general practitioner and four healthcare providers, including two Afghans residing in the camp, are responsible for providing healthcare for this population. A total of 628 Afghan refugees reside in the camp (327 men and 301 women); almost all female individuals in this population do not work outside their house, and the men are the breadwinners of the family, engaging mostly in manual labour occupations.

\section{Sample size and participants}

All camp residents who were 15 years of age or older were eligible to participate in the study, and all were enrolled.

\section{Data collection}

The study was designed mainly based on the WHO STEPwise approach to NCD risk factors surveillance [22]. The data were collected by the camp's healthcare providers in 2018. A 2-day training workshop was held for the staff before data collection, and their first day of data collection was supervised by 2 Ministry of Health experts.

Data were collected in three steps as follows: step 1: a gender-matched face-to-face interview for demographic information and behavioural measurements; step 2: physical and anthropometric measurements; step 3: biochemical measurements. All participants were invited to come to the clinic early in the morning, and were instructed to fast for at least $10 \mathrm{~h}$ in preparation for step 3. Furthermore, individuals with diabetes who were on medication (tablets or insulin) were reminded not to forget their medications and to bring them to the laboratory for subsequent use after step 3 was completed.

\section{Step 1: demographic information and behavioural measurements}

During an interview based on the Iranian national STEPS interview form, participants were asked about the number of members in the household, house residential area, average household monthly income, and their gender and age. Data on their nutrition, physical activity, and tobacco consumption were also collected. For nutritional status, the numbers of fruits and vegetables consumed on average in a typical day of the week were recorded. For physical activity, the participants were questioned about the quality and quantity of physical activity in the three domains of occupation, transport (walking, hiking or cycling) and recreation. Occupational physical activities were divided into two categories of vigorous or moderate intensity. Vigorous-intensity activities were those which lasted for at least 10 min continuously and caused a subjective perception of marked increase in respiration and heart rate (for example, carrying heavy loads, construction, forestry and drilling). Moderate-intensity activities lasted for at least $10 \mathrm{~min}$ and led to a subjective perception of slight increase in breathing and heart rate (for example, cleaning, washing by hand, milking cows by hand, planting and harvesting crops, and weaving). In a same way, activity during leisure time was recorded as two types: vigorous-intensity activities which made participants breathe much harder than normal, such as soccer, tennis, high-impact aerobics, and fast swimming, or moderate-intensity ones which made participants breathe somewhat harder than normal, such as cycling, jogging, and low-impact aerobics.

Furthermore, respondents were asked if a medical practitioner or healthcare provider had ever told them that they had diabetes mellitus (DM) or HTN. 


\section{Step 2: physical measurements}

Height and weight were measured with a mechanical telescopic measuring rod (Seca 222, Germany) and a digital scale (EF972, China), respectively. For height measurements, the participants were asked to remove their footwear and head gear, and those with a high hairdo were asked to press it down. In women, height was measured by female staff members in order to avoid awkwardness if participants needed to remove their veil or head scarf. To record body weight, all participants were asked the day before to wear light clothes, and were asked to remove their shoes and head gear, and to empty out their pockets.

For waist (WC) and hip circumference (HP) measurements, a constant tension tape was placed on the midpoint between the lowest palpable rib and the highest part of the iliac crest, and participants were asked to relax their arms at their sides; then WC was measured at the end of a normal expiration. Then the tape was positioned at the widest part of the buttocks, and HP was measured while their arms were relaxed at their sides.

Blood pressure (BP) was measured twice for each participant, once after step 1 was completed, and again at the end of step 3. An automatic digital sphygmomanometer (ALPK2 K2 1702) was used for BP measurements.

\section{Step 3: biochemical measurements}

A 5-mL sample of venous blood was collected in a tube while the participant was seated, and serum was separated by centrifugation immediately thereafter. Fasting plasma glucose (FPG), triglycerides (TG), total cholesterol (TC), high-density lipoprotein cholesterol (HDL-C), and low-density lipoprotein cholesterol (LDL-C) were measured with a chemical autoanalyser (Tokyo Boeki Prestige 24i, Japan). To determine serum levels of FPG and lipid profile, an enzymatic colorimetric method and enzymatic method respectively were used.

\section{Definition of variables}

All definitions were adopted from standard WHO definitions [23-25] as detailed below:

1. Unhealthy diet or inadequate fruit/vegetable consumption was defined as an average intake of fruit and vegetables of fewer than 5 servings per day [24].

2. Insufficient physical activity was considered as less than 75 min of vigorous-intensity physical activity or less than 150 min of moderate-intensity activity, or an equivalent combination of vigorous- and moderate-intensity physical activity to yield 600

MET-minutes during a typical week.

3. Elevated plasma glucose was defined as a plasma level $\geq 7.0 \mathrm{mmol} / \mathrm{L}(126 \mathrm{mg} / \mathrm{dL})$, and was also recorded if the participant was currently on medication for DM. The prediabetes stage was defined as a plasma glucose level between 5.5 and $7.0 \mathrm{mmol} / \mathrm{L}(100-125 \mathrm{mg} / \mathrm{dL})[24,26]$.

4. Elevated blood pressure was defined as systolic blood pressure (SBP) $\geq 140 \mathrm{mmHg}$ and/or diastolic blood pressure (DBP) $\geq 90 \mathrm{mmHg}$. Participants who were on medication for HTN were also considered to have elevated blood pressure. A SBP between 120 and $139 \mathrm{mmHg}$ or a DBP between 80 and 89 $\mathrm{mmHg}$ were recorded as prehypertension stage [24].

5. Individuals who met at least 3 of the following criteria were recorded as having metabolic syndrome: WC more than $89 \mathrm{~cm}$ in men and more than $79 \mathrm{~cm}$ in women, elevated TG $(\geq 150 \mathrm{mg} / \mathrm{dL})$, low HDL $(<40 \mathrm{mg} / \mathrm{dL}$ in men and $<50 \mathrm{mg} / \mathrm{dL}$ in women), SBP $\geq 130 \mathrm{mmHg}$ and/or $\mathrm{DBP} \geq 85 \mathrm{mmHg}$, or current use of medication for HTN, plasma glucose $>5.5 \mathrm{mmol} / \mathrm{L}$, or current medication for DM [27].

6. Abdominal obesity (abnormal waist-to-hip ratio) was defined as a waist-hip ratio $>0.90$ in males and $>0.85$ in females [27].

7. Abnormal waist-to-height ratio was considered waist-to-height ratio of more than 0.55 in men and more than 0.62 in women [28].

8. Body mass index was divided into four categories: below $18 \mathrm{~kg} / \mathrm{m}^{2}$, between $18 \mathrm{~kg} / \mathrm{m}^{2}$ and $25 \mathrm{~kg} / \mathrm{m}^{2}$, between $25 \mathrm{~kg} / \mathrm{m}^{2}$ and $30 \mathrm{~kg} / \mathrm{m}^{2}$, and above $30 \mathrm{~kg} /$ $\mathrm{m}^{2}$. These categories were considered respectively as underweight, healthy weight, overweight, and obese [27].

9. Abnormal lipid profile was defined as any of the followings: elevated TC ( $\geq 200 \mathrm{mg} / \mathrm{dL})$, high LDL $(\geq$ $160 \mathrm{mg} / \mathrm{dL})$, low HDL $(<40 \mathrm{mg} / \mathrm{dL}$ in men and $<50$ $\mathrm{mg} / \mathrm{dL}$ in women), or elevated TG $(\geq 150 \mathrm{mg} / \mathrm{dL})$ [29].

\section{Data cleaning and statistical analysis}

The data were cleaned with appropriate techniques as described previously [24]. Descriptive statistics were estimated. The world standard population distribution in 2000-25 was used to estimate the age-standardized prevalence of NCD risk factors and their confidence intervals. Crude and age-standardized prevalence and their Poisson 95\% confidence intervals (95\% CI) were estimated for abnormal levels of each risk factor. The chisquared test was used to evaluate the association of behavioural, physical and biological variables with age and 
gender. A $p$-value less than 0.05 was considered statistically significant. Statistical procedures were applied with Stata software (StataCorp SE, College Station, TX, USA).

\section{Ethical consideration}

Because the refugees in our study population were familiar with the clinical staff, the purpose and procedure of the study were explained to participants by the staff, and then written informed consent was obtained from all participants. In addition, within the camp each house had a unique code. We agreed that because of ethical considerations, the healthcare providers would use this code on the data sheets as an identifier to enhance anonymity, so that the researchers did not have access to the participants' names. The study was approved by the ethics committee of Shiraz University of Medical Sciences.

\section{Results}

The study population comprised all refugees older than 15 years in 133 families, and each family lived in a different house. There were 114 men with a mean age of 37.4 $( \pm 17.3)$ years, and 162 women with a mean age of 36.1 $( \pm 13.93)$ years. They were divided into 4 age groups: $15-$ $24,25-44,45-64$, and above 65 years.

The overall prevalence of consuming fewer than 5 servings of fruit/vegetables daily was $94.5 \%$ ( $94.7 \%$ in men and $94.4 \%$ in women; the difference between these two groups was not statistically significant at $p=0.916$ ). In all age groups, the percentage of individuals with inadequate fruit/vegetable consumption was above $90 \%$, and was highest (100\%) among those more than 65 years old. As noted above for gender, there was no significant association between age and unhealthy diet $(p=0.582$; Table 1).

Table 1 Behavioural, physical and biochemical risk factors for non-communicable diseases by age and gender group

\begin{tabular}{|c|c|c|c|c|c|c|c|c|c|c|c|}
\hline \multirow[t]{2}{*}{ Factor } & \multirow[t]{2}{*}{ No. } & \multirow{2}{*}{$\begin{array}{l}\% \text { Crude } \\
\text { prevalence } \\
\text { (CI) }\end{array}$} & \multirow{2}{*}{$\begin{array}{l}\% \\
\text { Standardized } \\
\text { prevalence } \\
\text { (CI) }\end{array}$} & \multicolumn{8}{|c|}{ Prevalence in age subgroups (\%) } \\
\hline & & & & $\begin{array}{l}\text { Men \% } \\
\text { (CI) }\end{array}$ & $\begin{array}{l}\text { Women \% } \\
\text { (CI) }\end{array}$ & $\begin{array}{l}P \text { - } \\
\text { value }\end{array}$ & $\begin{array}{l}15- \\
24\end{array}$ & $\begin{array}{l}25- \\
44\end{array}$ & $\begin{array}{l}45- \\
65\end{array}$ & $\begin{array}{l}\text { Above } \\
65\end{array}$ & $\begin{array}{l}p- \\
\text { value }\end{array}$ \\
\hline Total number & 276 & 100 & 100 & 114 & 162 & - & 69 & 132 & 57 & 18 & - \\
\hline \multicolumn{12}{|l|}{ Behavioural variables } \\
\hline Fruit/vegetables $<5$ servings & 261 & $94(91-96)$ & $69(67-71)$ & $94(88-98)$ & $94(89-97)$ & 0.916 & 94 & 93 & 96 & 100 & 0.582 \\
\hline Insufficient physical activity & 50 & $18(13-23)$ & $14(10-18)$ & $11(6-18)$ & $22(16-30)$ & 0.015 & 15 & 16 & 19 & 33 & 0.352 \\
\hline Tobacco use & 26 & $9(6-13)$ & $8(4-11)$ & $18(11-26)$ & $3(1-7)$ & $<0.001$ & 10 & 9 & 10 & 5 & 0.928 \\
\hline Known diabetes & 7 & $2(1-5)$ & $1(0.3-3)$ & $\begin{array}{l}0.8(0.02- \\
4)\end{array}$ & $3(1-7)$ & 0.141 & 0 & 0.7 & 10 & 0 & $<0.001$ \\
\hline Prediabetes & 16 & $5(3-9)$ & $4(2-7)$ & $4(1-9)$ & $6(3-11)$ & 0.400 & 5 & 3 & 10 & 5 & 0.346 \\
\hline $\begin{array}{l}\text { Elevated fasting plasma } \\
\text { glucose }\end{array}$ & 9 & $3(1-6)$ & $2(0.6-3)$ & $1(0.2-6)$ & $4(1-8)$ & 0.237 & 1 & 1 & 10 & 0 & 0.007 \\
\hline Known HTN & 45 & $16(12-21)$ & $13(9-16)$ & $14(8-21)$ & $17(12-24)$ & 0.392 & 1 & 9 & 38 & 55 & $<0.001$ \\
\hline Prehypertension & 62 & $22(17-27)$ & $15(11-19)$ & $24(16-33)$ & $20(14-28)$ & 0.484 & 18 & 26 & 22 & 5 & 0.193 \\
\hline Elevated blood pressure & 56 & $20(15-25)$ & $16(12-19)$ & $20(13-28)$ & $20(14-27)$ & 0.968 & 7 & 12 & 42 & 55 & $<0.001$ \\
\hline Metabolic syndrome & 39 & $14(10-18)$ & $10(7-13)$ & $7(3-13)$ & $19(13-26)$ & 0.004 & 7 & 12 & 24 & 22 & 0.027 \\
\hline \multicolumn{12}{|l|}{ Physical variables } \\
\hline Abnormal waist-to-hip ratio & 141 & $51(45-57)$ & $37(32-42)$ & $39(30-49)$ & $59(51-66)$ & 0.001 & 28 & 51 & 77 & 50 & $<0.001$ \\
\hline $\begin{array}{l}\text { Abnormal waist-to-height } \\
\text { ratio }\end{array}$ & 79 & $28(22-35)$ & $27(22-32)$ & $42(31-55)$ & $19(13-27)$ & $<0.001$ & 26 & 29 & 29 & 27 & 0.956 \\
\hline Metabolically healthy obesity & 35 & $12(8-17)$ & $8(5-11)$ & $12(6-19)$ & $12(8-19)$ & 0.867 & 8 & 18 & 7 & 0 & 0.019 \\
\hline Underweight & 16 & $5(3-9)$ & $6(4-9)$ & $7(3-13)$ & $4(2-9)$ & 0.467 & 11 & 1 & 5 & 16 & 0.006 \\
\hline Overweight & 68 & $24(19-30)$ & $19(15-23)$ & $24(16-33)$ & $24(18-32)$ & 0.980 & 13 & 27 & 29 & 33 & 0.070 \\
\hline Obese & 55 & $19(15-25)$ & $13(10-16)$ & $15(9-23)$ & $22(16-30)$ & 0.149 & 13 & 25 & 21 & 5 & 0.088 \\
\hline \multicolumn{12}{|l|}{ Biochemical variables } \\
\hline Elevated total cholesterol & 107 & $38(32-44)$ & $28(23-33)$ & 38 (29-44) & $38(31-46)$ & 0.961 & 20 & 38 & 59 & 44 & $<0.001$ \\
\hline Elevated TG & 36 & $13(9-17)$ & $9(5-12)$ & $11(6-18)$ & $14(9-20)$ & 0.497 & 2 & 18 & 12 & 16 & 0.023 \\
\hline High LDL & 9 & $3(1-6)$ & $2(0.6-3)$ & $2(0.5-7)$ & $3(1-7)$ & 0.621 & 0 & 4 & 3 & 5 & 0.344 \\
\hline Low HDL & 113 & $40(35-46)$ & $29(25-34)$ & $16(10-24)$ & $58(50-65)$ & $<0.001$ & 42 & 40 & 42 & 33 & 0.920 \\
\hline Abnormal lipid profile & 191 & $69(63-74)$ & $49(45-54)$ & $54(44-63)$ & 79 (72-85) & $<0.001$ & 55 & 68 & 84 & 77 & 0.004 \\
\hline
\end{tabular}


The overall prevalence of insufficient physical activity was $18.1 \%$; this prevalence was higher in women $(22.8 \%$, 37 individuals) than men (11.4\%, 13 individuals), and the difference between these two groups was statistically significant at $p=0.015$. Furthermore, the highest rate of physical inactivity was found among those older than 65 years (33.3\%); however, no significant relationship was detected between age groups and low levels of physical activity $(p=0.352$; Table 1$)$.

The overall prevalence of tobacco consumption (both smoked and smokeless tobacco products) was $9.4 \%$, with a significantly higher proportion in males $(18.4 \%, 21$ individuals) than females (3\%, 5 individuals; $p<0.001$ ). There were no statistically significant differences between age groups in the percentage of individuals who used tobacco products $(p=0.928$; Table 1$)$.

Elevated FPG was recorded in 2.8\% (8 individuals) of the population, of whom $1.7 \%$ ( 2 individuals) were males and $3.7 \%$ (6 individuals) were females. Among these participants, 6 individuals were aware of their diabetes and were using medication. The prevalence of participants with elevated FPG was highest in the 45-64-year-old age group ( $p=0.007$; Table 1$)$.

In the target population, $20.2 \%$ of the participants had elevated BP, with no statistically significant difference between men and women $(p=0.968)$. Eleven participants were unaware of having elevated BP. The percentage of participants with elevated BP showed a statistically significant relationship with age, and the prevalence was highest among individuals older than 65 years $(p<0.001$; Table 1).

The prevalence of central obesity was $51.2 \%$, and this prevalence was significantly higher in women than men $(p=0.001)$. There was also a statistically significant relationship between age group and the prevalence of central obesity $(p<0.001$; Table 1$)$.

In the target population, a total of 191 persons (69.2\%) had at least one abnormality in lipid profile components (high TG, TC and LDL-C, and low HDL-C). The prevalence of abnormal profiles was statistically significantly higher in women than in men $(\mathrm{p}<0.001)$. Similarly, age had a statistically significant relationship with lipid profile status ( $p=0.004$; Table 1$)$.

Among behavioural, physical and biochemical risk factors, unhealthy diet, abnormal waist-to-hip ratio and abnormal lipid profile had the highest prevalence (Table 1).

\section{Discussion}

The study showed that $94 \%$ of the Afghan refugees consumed fewer than 5 servings of fruit/vegetables on a typical day; this proportion reached $100 \%$ in individuals older than 65 years, among whom none reported that their diet met the recommendation proposed by the WHO. This prevalence of unhealthy diet composition was extremely higher than the prevalence of inadequate fruit/vegetable consumption in Iran [19]. One of the most important barriers is the lack of knowledge about recommended daily intakes; almost all the refugee population in the present study was unaware of such recommendations. The affordability of fruit and vegetables is another determinant of intake, and its influence has been exacerbated due to inflation and currency collapse as a result of economic sanctions.

Prevalence of low level of physical activity in the study population was only $18 \%$. This is very lower than reported prevalence in Iran $(56.17 \%)$ and also in Fars province (nearly 57\%) [19]. One factor contributing to this discrepancy between the general population and refugee population is that unlike local residents, refugees are more often forced by necessity to accept hard and physically active jobs, such as carrying heavy loads, drilling and mining. Furthermore, the refugee population has far less access to facilities that lessen physical activity and give rise to a sedentary lifestyle, such as television. The present findings also showed that the prevalence of suboptimal physical activity was higher among women than men. It may be mainly a result of beliefs that restrict women's physical activity mainly to indoor activities.

The findings indicated that $9 \%$ of the study population used tobacco, and $3.26 \%$ of them smoked tobacco, which is much lower than the prevalence of smoking in the general population of Fars province. This low prevalence of smoking may be result of higher consumption of a smokeless dipping tobacco called naswar, as $13 \%$ of the target group reported using mouth snuff products.

According to the International Diabetes Federation (IDF), in Middle Eastern and north African countries, prevalence estimates of diabetes range from 3.5\% in Yemen to $18.2 \%$ in Saudi Arabia [30]. It has been reported around $10 \%$ for the Fars province [19]. A meaningfully lower prevalence of elevated FPG (3\%) was observed in the study population. This finding is consistent with their higher physical activity and lower rates of obesity, central obesity and dyslipidaemia. However, the present study showed that $5 \%$ of them were pre-diabetic. Estimated prevalence of HTN among Afghan refugees (20\%) was similar to the reported prevalence at national and provincial levels $[19,31]$. This figure indicates that for both FPG and blood pressure status, preventive measures such as lifestyle modifications and medical interventions, if indicated, should be considered.

Laboratory analyses showed that $69 \%$ of the refugee population had some degree of abnormality in their lipid profile, i.e. in cholesterol levels, TG levels, or both. According to the Iran STEPS study in 2016, the national prevalence of hypercholesterolaemia and hypertriglyceridemia was found to be 22 and $27.8 \%$, respectively [19]. In a study in Jalalabad in 2013, the prevalence of 
hyperglycaemia was reported to be $31.4 \%$, i.e., far higher than the prevalence in the Afghan refugee population studied here (13\%). This significant difference may reflect the fact that less healthy dietary patterns (e.g., fast foods, junk foods, and high-salt meals) and lifestyle choices (e.g., sedentary workplace, passive hobbies) have not yet become part of refugees' regular habits.

Two limitations of the study should be noted. First, because of executive and legal issues, this study was conducted in a single refugee camp. According to reports from authorities and experts in this field, social determinants of health in this population - including socioeconomic status, ethnicity, age and gender structure of the population, and access to health - are quite similar to those at most registered settlements located in Iran; however, data security conditions did not allow us to undertake a statistical analysis of these factors. Second, there was no report on national NCD surveillance in Afghanistan, and the prevalence and risk factors for NCDs have been studied so far only in Kabul and Jalalabad City. However, even in these two studies, a representative sample of the whole population was not considered, and the WHO definitions were not used for all risk factors. This issue restricted us to comparing our study population with their peers in the general population of Afghanistan.

\section{Conclusion}

Our study indicated that except for the dietary risk factor of inadequate fruit and vegetable intake, the prevalence of other risk factors was lower than in the Iranian provincial and national population. The study highlights that improving nutritional status deserves more consideration in the refugee population, and that actions are needed to deal with this issue. Fortunately, removing or reducing this risk factor is more feasible than changing lifestyle-related risk factors. Raising awareness about the importance of a healthy diet, along with providing more affordable fruits and vegetables, are two effective steps toward improving dietary status in the refugee population.

\section{Abbreviations \\ NCD: Non-communicable diseases; UNHCR: United Nations High Commissioner for Refugees; WHO: World Health Organization; HTN: Hypertension; DM: Diabetes mellitus; HP: Hip circumference; WC: Waist circumference; BP: Blood pressure; LDL-C: Low-density lipoprotein cholesterol; HDL-C: High-density lipoprotein cholesterol; TC: Total cholesterol; TG: Triglycerides; FPG: Fasting plasma glucose; SBP: Systolic blood pressure; DBP: Diastolic blood pressure; IDF: International Diabetes Federation}

\section{Acknowledgements}

We express special thanks to Lambed Tatah, Regina Mendela Duperval, Sabiha Nasrin, Abinet Shiferaw Worke, Jane Osindo, Alaaddin Salih, Mohsen Moghadami, Ali Ardalan and Adam Levine for supporting us in this research, and thank K. Shashok (AuthorAID in the Eastern Mediterranean) for improving the use of English in the manuscript.

\section{Authors' contributions}

MJM, BR, AH and HMV conceptualized and designed the study and critically reviewed the manuscript. ET (both Erfan Taherifard and Ehsan Taherifard) participated in data collection, wrote the manuscript, and critically reviewed the manuscript. All authors read and approved the final manuscript.

\section{Funding}

This study was funded by Shiraz University of Medical Sciences (No.1396-01109-16710) and the Humanitarian Innovation Initiative (No. EN463896

PRG136). Both funders contributed to the cost of conducting the study.

Availability of data and materials

The datasets used and/or analysed during the current study are available from the corresponding author on reasonable request.

\section{Declarations}

\section{Ethics approval and consent to participate}

Informed consent was obtained from all participants. For participants younger than 18 years old, written informed consent for participation was also obtained from their parents. All methods of the study were carried out in accordance with relevant guidelines and regulations. The study was approved by the ethic committee of Shiraz University of Medical Sciences (IR.SUMS.REC.1398.763).

Consent for publication

Not applicable.

\section{Competing interests}

The authors declare no conflicts of interest.

\section{Author details}

${ }^{1}$ MPH Department, Medical School, Shiraz University of Medical Sciences, Setad Square, Shiraz, Fars, Iran. ${ }^{2}$ Trauma Research Center, Shahid Rajaee (Emtiaz) Trauma Hospital, Shiraz University of Medical Sciences, Shiraz, Iran. ${ }^{3}$ Shiraz University of Medical Sciences, Shiraz, Iran. ${ }^{4}$ Department of Disaster Public Health, School of Public Health, Tehran University of Medical Sciences, Tehran, Iran

Received: 9 February 2021 Accepted: 19 February 2021

Published online: 05 March 2021

\section{References}

1. Matlin SA, Depoux A, Schütte S, Flahault A, Saso L. Migrants' and refugees' health: towards an agenda of solutions. Public Health Rev. 2018;39:27.

2. Silove D, Steel Z, Bauman A, Chey T, McFarlane A. Trauma, PTSD and the longer-term mental health burden amongst Vietnamese refugees : a comparison with the Australian-born population. Soc Psychiatry Psychiatr Epidemiol. 2007:42(6):467-76.

3. Vaage AB, Thomsen PH, Silove D, Wentzel-Larsen T, Van Ta T, Hauff E. Longterm mental health of Vietnamese refugees in the aftermath of trauma. $\mathrm{Br} J$ Psychiatr. 2010;196(2):122-5.

4. Giallo R, Riggs E, Lynch C, Vanpraag D, Yelland J, Szwarc J, Duell-Piening P, Tyrell L, Casey S, Brown SJ. The physical and mental health problems of refugee and migrant fathers: findings from an Australian population-based study of children and their families. BMJ Open. 2017;7(11):e015603.

5. Ackerman LK. Health problems of refugees. J Am Board Fam Pract. 1997; 10(5):337-48.

6. Abbas M, Aloudat T, Bartolomei J, Carballo M, Durieux-Paillard S, Gabus L, Jablonka A, Jackson Y, Kaojaroen K, Koch D, et al. Migrant and refugee populations: a public health and policy perspective on a continuing global crisis. Antimicrob Resist Infect Control. 2018:7:113.

7. Rehr M, Shoaib M, Ellithy S, Okour S, Ariti C, Ait-Bouziad I, van den Bosch P, Deprade A, Altarawneh M, Shafei A, et al. Prevalence of non-communicable diseases and access to care among non-Camp Syrian refugees in northern Jordan. Confl Heal. 2018;12:33.

8. Agyemang C, van den Born BJ: Non-communicable diseases in migrants: an expert review. Journal of travel medicine 2018.

9. Organization WH: Global status report on noncommunicable diseases 2014. 2014. 
10. Lopez AD, Murray CC. The global burden of disease, 1990-2020. J Nat Med. 1998:4(11):1241.

11. Engelgau MM, Sampson UK, Rabadan-Diehl C, Smith R, Miranda J, Bloomfield GS, Belis D, Narayan KMV, National Health L. Blood instituteUnitedHealth Global Health centers of excellence C: tackling NCD in LMIC achievements and lessons learned from the NHLBI-UnitedHealth Global Health centers of excellence program. Glob Heart. 2016;11(1):5-15.

12. De Maeseneer J, Roberts RG, Demarzo M, Heath I, Sewankambo N, Kidd MR, van Weel C, Egilman D, Boelen C, Willems S. Tackling NCDs: a different approach is needed. Lancet (London, England). 2012;379(9829):1860-1.

13. Nethan S, Sinha D, Mehrotra R. Non Communicable Disease Risk Factors and their Trends in India. Asian Pac J Cancer Prev. 18(7):2005-10.

14. Hoodfar H. The Long Road Home: Adolescent Afghan Refugees in Iran Contemplate 'Return. J Years Conflict. 2008;25:165.

15. Maleki S, Cowan L: Iran,Factsheet,1 July 2017. In.; 2017: 4.

16. Abbasi-Shavazi M, Glazebrook D, Mahmoudian H, Jamshidiha G, Sadeghi R: Return to Afghanistan? A study of Afghans living in Tehran, Mashhad, and Zahedan. Retrieved October 30 th 2016. In.; 2005.

17. Tober DM, Taghdisi MH, Jalali M. "Fewer children, better life" or "as many as god wants?" Family planning among low-income Iranian and afghan refugee families in Isfahan, Iran. Med Anthropol Q. 2006;20(1):50-71.

18. Zahedi A. Transnational marriages, gendered citizenship, and the dilemma of Iranian women married to afghan men. J Iran Stud. 2007;40(2):225-39.

19. Education Irolmoham: Atlas of non-communicable diseases risk-factors surveillance in the Islamic republic of Iran-STEPs 2016, In.; 2016.

20. Saeed KMI. Prevalence of risk factors for non-communicable diseases in the adult population of urban areas in Kabul City, Afghanistan. Cent Asian J Glob Health. 2014;2:69.

21. Saeed KM, Rasooly MH, Alkozai A. Prevalence of risk factors for noncommunicable diseases in Jalalabad city, Afghanistan, evaluated using the WHO STEPwise approach. East Med Health J. 2016;21(11):783-90.

22. Organization WH: The STEPS instrument and support materials, 2013. In.

23. Riley L, Guthold R, Cowan M, Savin S, Bhatti L, Armstrong T, Bonita R. The World Health Organization STEPwise approach to noncommunicable disease risk-factor surveillance: methods, challenges, and opportunities. Am J Public Health. 2016;106(1):74-8.

24. WHO: WHO STEPS Surveillance Manual. In.: 2017.

25. Olawuyi AT, Adeoye IA. The prevalence and associated factors of noncommunicable disease risk factors among civil servants in Ibadan, Nigeria. PLoS One. 2018;13(9):e0203587.

26. American Diabetes A. Diagnosis and classification of diabetes mellitus. Diab Care. 2010;33(Suppl 1):562-9.

27. Jameson JL: Harrison's principles of internal medicine: McGraw-hill education; 2018

28. Hadaegh F, Zabetian A, Sarbakhsh P, Khalili D, James WP, Azizi F. Appropriate cutoff values of anthropometric variables to predict cardiovascular outcomes: 7.6 years follow-up in an Iranian population. Int J Obes (2005). 2009:33(12):1437-45.

29. National Cholesterol Education Program (NCEP) Expert Panel on Detection, Evaluation, and Treatment of High Blood Cholesterol in Adults (Adult Treatment Panel III) final report. Circulation. 2002;106(25):3143-421.

30. Cho N, Shaw J, Karuranga S, Huang Y, da Rocha FJ, Ohlrogge A, BJDr M, Practice C. IDF Diabetes Atlas: Global estimates of diabetes prevalence for 2017 and projections for 2045. 2018;138:271-81.

31. Ahmad Kousha DKE, Jalil Kouhpayezadeh, Kambiz Abachizadeh, Ali Rafei, Fereshteh Salavati, Mahboobeh Darman, Parisa Rezanejad, Abbas Pariani: Iran NCD Risk Factors STEPs Report. In.; 2011.

\section{Publisher's Note}

Springer Nature remains neutral with regard to jurisdictional claims in published maps and institutional affiliations.

Ready to submit your research? Choose BMC and benefit from:

- fast, convenient online submission

- thorough peer review by experienced researchers in your field

- rapid publication on acceptance

- support for research data, including large and complex data types

- gold Open Access which fosters wider collaboration and increased citations

- maximum visibility for your research: over $100 \mathrm{M}$ website views per year

At BMC, research is always in progress.

Learn more biomedcentral.com/submissions 